\title{
Correction to: A novel model for sustainable waste collection arc routing problem: Pareto-based algorithms
}

\author{
Erfan Babaee Tirkolaee ${ }^{1}$ (D) Alireza Goli ${ }^{2}$. Selma Gütmen ${ }^{3}$. \\ Gerhard-Wilhelm Weber ${ }^{3,4} \cdot$ Katarzyna Szwedzka ${ }^{3}$
}

(c) Springer Science+Business Media, LLC, part of Springer Nature 2022

\section{Correction to: Annals of Operations Research https://doi.org/10.1007/s10479-021-04486-2}

This erratum published as several formatting issues were noticed with Tables and equations. Original article has been corrected.

Publisher's Note Springer Nature remains neutral with regard to jurisdictional claims in published maps and institutional affiliations.

The original article can be found online at https://doi.org/10.1007/s10479-021-04486-2.

$\bowtie \quad$ Erfan Babaee Tirkolaee

erfan.babaee@istinye.edu.tr

Alireza Goli

goli.a@eng.ui.ac.ir

Selma Gütmen

selma.gutmen@doctorate.put.poznan.pl

Gerhard-Wilhelm Weber

gerhard.weber@put.poznan.pl

Katarzyna Szwedzka

katarzyna.szwedzka@ put.poznan.pl

1 Department of Industrial Engineering, Istinye University, Istanbul, Turkey

2 Department of Industrial Engineering and Future Studies, Faculty of Engineering, University of Isfahan, Isfahan, Iran

3 Faculty of Engineering Management, Poznan University of Technology, Poznan, Poland

4 Institute of Applied Mathematics, Middle East Technical University, Ankara, Turkey 